tal manera que no podemos distinguir uno del otro. Según James Hall ${ }^{21}$ en la poesía alegórica de Brant se narra sobre el barco lleno de locos que parten hacia «el paraíso de los locos» - Narragonia - De tal manera, la poesía de Brant sirve como medio para un comentario satírico de la locura de la época en un amplio sentido de la palabra: abarca la vida disipada, vicios de todo tipo, ebriedad, obscenidad, venalidad de los abogados, corrupción, etc.

En nuestro caso se añade un nivel de significado más: el timonel de la popa en el grabado de madera de Pilsen tiene en su sombrero una concha, el signo de peregrinos relacionado con el culto de Santiago y con las peregrinaciones, sobre todo a Santiago de Compostela ${ }^{22}$. Podemos entonces, considerar este barco representado en el primer escrito checo sobre el descubrimiento del Nuevo Mundo, inspirado en la ilustración que acompaña a la Nave de los Locos de Brant - conforme a las ideas arriba mencionadas y en el contexto de la edición checa- también como un barco de peregrinos que se dirige hacia la nueva tierra prometida, América, cuyos rasgos paradisíacos subrayó el descubridor mismo adhiriéndose al espíritu de la idealización utópica de la época, y por lo tanto, muy distante a la realidad ${ }^{23}$.

PAvel StepÁNeK

\title{
CALIGRAFÍA Y GRABADO EN TORNO A D. PEDRO PAREDES
}

Jonathan Richardson (1719) sugirió que el modo más apropiado de juzgar una obra de arte era situarla en el medio propio de la escuela local o en el período histórico al cual pertenecía. Pero igual de interesante es ver, en determinados hechos artísticos, la fuente de inspiración de tendencias actuales o la posible raíz de nuevas disciplinas.

La escritura es uno de los grandes inventos de la humanidad, es un lenguaje comunicativo que ha hecho posible la historia, siendo su inventor mítico el dios egipcio Tot. Es también algo cuyo dominio la mayoría de la gente da hoy por supuesto. Ya adultos, apenas si nos paramos a pensar en el método mental y físico gracias al cual nuestros pensamientos se codifican y transforman en símbolos sobre un soporte, sea una hoja de papel, una pantalla, o en bytes de información en un disquete de ordenador.

Mucho menos preocupa la técnica gráfica que se utiliza en estos procesos, o el ritmo corporal cuando se escribe.

Si se contempla la historia de la escritura es posible observar la riqueza que aúna este lenguaje, de paleta policroma, debido a la vasta influencia que ha tenido y que abarca muchas culturas e idiomas, prácticamente todos los períodos del desarrollo humano. Se sirve de ideas e información tomadas de una serie de disciplinas como Antropología, Arqueología, Historia del Arte, Economía, Lingüística, Técnicas de reproducción, Dibujo, Matemáticas, Historia política y social, Psicología y Teología, Literatura y manuscritos medievales, y sin ánimo de hacer interminable esta lista, alude a la caligrafía, a la tipografía y a la imprenta.

\footnotetext{
${ }^{21}$ J. Hall, op. cit. en la nota 3, p. 251.

${ }^{22}$ Viz Pavel Stepánek, Za sv.. Jakubem s «hyspánským strychem» pres Plzen. (En pos de Santiago con el «escudo hispánico» atravesando Pilsen). Ponencia presentada en la conferencia científica con ocasión de la exposición El gótico de la Bohemia Occidental en la Galería Nacional de Praga. En imprenta.

${ }^{23}$ Kolumbúv lodní deník (El cuaderno de bitácora de Colón. Con prefacio de Josef Susta. Novina, Praha, 1942, pp. 206214. Daniela Hodrová, Román zasvecení (La novela de consagración). Praha 1993, p. 190 recuerda que el espacio de iniciación de la Edad Media, el espacio interior en el modelo horizontal de la consagración, se expresa, entre otro, también con los puntos cardinales. En el Oeste se encuentran las islas y el imperio de los muertos, mientras que en el Este, el reino de Dios.
}

$A E A, \mathrm{LXXV}, 2002,297$, pp. 51 a 88 
En lo esencial, la manera de escribir actual, a principio de este milenio de la presente era, no se diferencia de la de los antiguos egipcios; es decir, la síntesis estructurada de una idea o pensamiento a través de un código de símbolos representativos de una cultura.

Aristóteles llamó a la unidad básica del lenguaje, tanto escrito como hablado, gramma. Ferdinand de Saussure, el fundador de la lingüística moderna, dijo del lenguaje que es comparable a una hoja de papel: »El pensamiento está en una de las caras, y el sonido en la otra. De la misma manera que es imposible coger unas tijeras y cortar una cara de una hoja de papel sin cortar al mismo tiempo la otra, también lo es en el idioma aislar el sonido del pensamiento, o el pensamiento del sonido» 1 .

Lo que se tiene más claro en los procesos del lenguaje oral, apenas se comprende todavía en los de la lectura y la escritura, aunque ésta no se pueda disociar del habla, pues las palabras y los sistemas de escritura dependen tanto de sonidos como de símbolos, respectivamente. En general se puede decir que los sistemas de escritura cambian mucho más que los de la lengua hablada, ya que en aquellos hay una evolución de signos, un oficio y un arte. En la China clásica, por ejemplo, la escritura «shu» era un arte comparable a la pintura, la poesía y la música, y superior en ocasiones a éstas.

Caligrafía es una palabra de raíces griegas. Viene de «cali», que traducido quiere decir hermoso y bello de contemplar, y "grafía», que significa trazado, dibujo o escritura manual. Luego caligrafía significa arte o manera de escribir con belleza y gracia, conceptos abstractos de múltiples significados y muy unidos a criterios de cultura y época.

El trabajo caligráfico requiere una previa conceptualización, es preciso discernir qué es lo que se quiere conseguir en cada caso, qué características imprimir̀ al escrito y cual son los principales estilos, pues los artistas gráficos necesitan disponer de los máximos conocimientos, en estos aspectos con el fin de poder acometer toda clase de escritura adecuadamente.

Inventada, descubierta accidentalmente o evolucionada, como se prefiera, se difundió por todo el mundo a partir de Mesopotamia, educándose en ella con la calificación de escribiente $\mathrm{y}$ artesano, o ilustrador.

En el siglo x, en España, se desarrolla la caligrafía y la ornamentación y se producen obras de gran calidad. Surgen las escuelas Andaluzas, Toledana, Castellana y Leonesa. En el siglo XVI aparece Juan de Yciar y Francisco Lucas; más adelante Casanova y Diaz Morante; de este modo la escritura en España evolucionó paralelamente a la de los demás países y al mismo nivel.

Se introduce, posteriormente, como arte de la caligrafía en la formación del niño y, como consecuencia, en la formación del maestro en el siglo xIX, teniéndose el concepto del dibujo como auxiliar de ella: «La construcción de las pautas y el análisis geométrico de las letras y demás signos gráficos serían imposibles sin conocer el Dibujo Lineal; la ornamentación de la letra se funda en el dibujo de adorno y de figura; el que sabe de Dibujo tiene mejor gusto para escribir y el Dibujo, por último, enseña a manejar muchos instrumentos que ha de usar también el que se dedica al ejercicio de la Escritura» ${ }^{2}$.

A partir de esas fechas, poco puede decirse en la caligrafía española, que, actualmente, apenas, se práctica en este país, ya que ha ido transformándose en formas más espontáneas del trazo legible, hasta la tipografía más estrictamente normalizada. Es curioso, no obstante, ver en el ámbito global del arte y más concretamente en algunos artistas, que existe una cierta tendencia de retorno a ella, con concepciones nuevas pero, de alguna manera, inspiradas en sus grafismos.

1 Robinson, A. Historia de la Escritura. Edit. Destino 1996 Barcelona, p. 11

${ }^{2}$ Blanco y Sánchez, R. Arte de la escritura y de la caligrafía. Edit Hernando. Madrid 1927, p. 19.

AEA, LXXV, 2002, 297, pp. 51 a 88 
El caso del que aquí se trata es un manual de instrucciones prácticas en el arte de escribir de D. Pedro Paredes, alicantino, grabador calcográfico y escritor de todas formas de letras y educador, manual publicado y editado en Murcia 1792, en la Imprenta de la VIUDA de Felipe Teruel.

La finalidad de hablar sobre él, no solamente es dar a conocer su obra, en sí interesante, sino el ver como se aúnan en el arte de la caligrafía y en este manual, la técnica caligráfica y de la reproducción artística, muy de acuerdo con la historia del momento, y en el caso concreto de Murcia.

Paredes publicó diferentes cuadernos anteriores a este fruto de diez años de docencia, publicaciones tales como: Prontuario, colección de Muestras y Falsas reglas, publicada para utilidad y alivio de los maestros pobres, que no podían adquirir un costoso arte completo de escribir, tal y como él mismo comentaba. Un reducido Manual a beneficio de los Niños de Primeras Letras, para que, introducido en sus Escuelas, facilitara el deletreo y lección seguida de las dicciones, siguiendo a estas obras la tratada, El Arte de Escribir, Instrucciones prácticas, resumiendo de ella: «Ya mirado en sus principios y reglas fundamentales, ya en sus diversos y singulares caracteres de Letra, ya en la formación y hermosura de los rasgos y giros de la pluma, ya finalmente en la parte que puede considerarse como adorno y perfección del Arte: prescribiendo la norma con que deben formarse los Abecedarios para Libros de Coro, Inscripciones, Títulos y otros varias curiosidades de Pluma» ${ }^{3}$.

La obra iba dirigida a los jóvenes aplicados, deseosos de perfeccionarse en el Arte de Escribir y las ventajas que esto les proporcionaba, pues varios establecimientos dependían, en esa época, de la habilidad y maestría del ejercicio de la pluma.

El método que utiliza en su obra, obedecía a la explicación estructurada en forma de «dialogo» entre Maestro y Discípulo, tal como versa en su portada. Se ilustra cada momento crítico con su correspondiente grabado, obra del mismo autor, hecho que constata reiteradamente en sus gráficos.

Para un discurso ordenado se comentará dicho cuaderno desde su primer grabado, configurado éste con el tema al cual dedica su obra, La Soberana Anunciación de María Santísima.

El tratamiento de líneas se basa en el movimiento de rúbricas, muy frecuentes en el acompañamiento de textos escritos en letra cursiva inglesa y que, en el campo del dibujo, son clasificados como trazos de pluma o rasgueo, usándose éstos para enfatizar una temática, un texto o construir unas formas. El maestro de este arte fue Schwandner, siglo XvI, aunque contemplando el XVIII, se puede observar el mismo estilo en el grabado de Pedro Díaz Morante titulado «Muestra caligráfica» ${ }^{4}$.

Para acometer el arte del rasgueo se ha de coger la pluma casi vertical, sin apoyar la muñeca en el papel, de esta forma las curvas serán más armoniosas, y presionando la pluma se añadirán, en caso necesario, diferentes tipos de trazos gruesos; es casi un ritual que requiere un tiempo de preparación, una armonización de mente y un ritmo corporal. Muchos de los calígrafos de hoy en día utilizan este método, con una mirada algo perdida, que quiere retomar o recoger la autenticidad de una técnica o un estilo, adaptando esa esencia, llamada también idea, al mundo actual y a las necesidades que se derivan de él.

Hay que tener en cuenta que las modernas técnicas de reproducción y los usos que se dan a la caligrafía en el mundo moderno de la edición y de la publicidad, requieren cada vez más justeza. Obsérvese como caso ilustrativo de este comentario el gráfico que se aporta de la ca-

\footnotetext{
${ }^{3}$ Paredes, P. Instrucciones Prácticas en el Arte de Escribir. Edit. Imprenta la Viuda, Murcia. 1792. Prólogo del Manual.

${ }^{4}$ Carrete, J. / varios. Estampa Cinco Siglos de Imagen Impresa. Edita Ministerio de Cultura, Dirección General de B.A., Archivos y Bibliotecas, 1985, p. 151.
}

AEA, LXXV, 2002, 297, pp. 51 a 88 

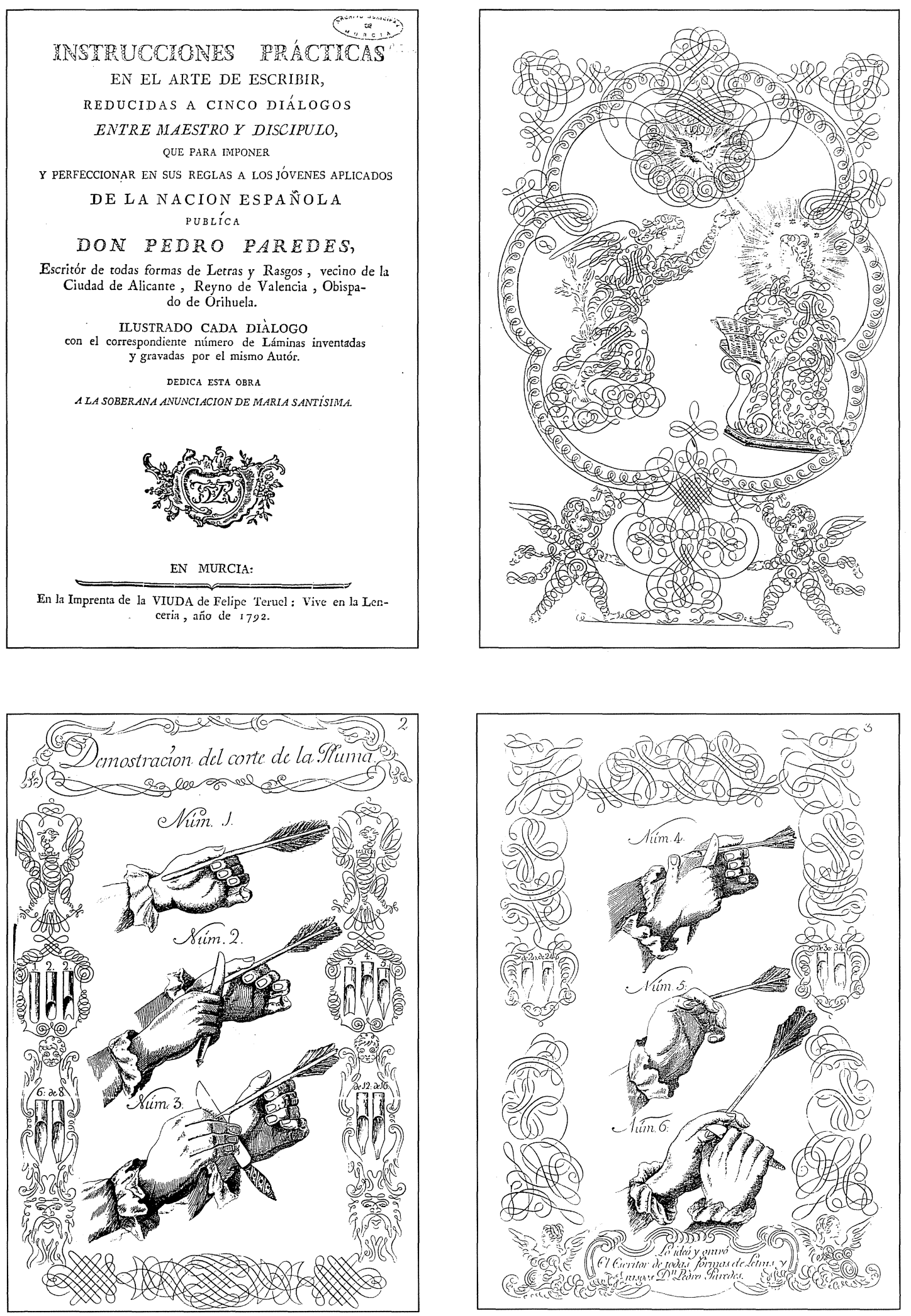

Figs. 1, 2, 3 y 4. Pedro de Paredes. Instrucciones prácticas en el arte de escribir. Grabados ilustrativos.

AEA, LXXV, 2002, 297, pp. 51 a 88 
ligrafía actual realizada por Larcher y cualquier fragmento del grabado último de Paredes en su orla, o los diseños de David Quay, Bill Ficha y Tony Foster, que en su inspiración retornan la mirada a esta época.

Continua este Manual de Instrucciones con el Primer Diálogo, dedicado a «El Modo de Cortar la Pluma», que como él mismo apunta, tanto conduce para la formación y hermosura de la Letra.

El proceso queda básicamente demostrado en dos láminas grabadas, pensadas como ilustración de textos en seis pasos, de los que se seleccionan, por su curiosidad, algunos de sus comentarios: Se escoge un cortaplumas de temple suave; se eligen las plumas en función de cinco condiciones, a) que sean duras, b) redondas y no esquivadas, c) que sean limpias sin vetas blancas, d) claras y transparentes con el casco firme y e) preferiblemente del ala derecha. No deshecha, sin embargo, las de otras zonas, pues son útiles las regulares inferiores, que no se utilizan por delgadas, para ejecutar líneas muy sutiles en la realización de Modelos, Mapas o Planos. Las de más precisión son las de Cuervo, utilizadas por los Académicos del dibujo en Roma, y las de Cisne, más gruesa y con más peso, para rallar mapas, cuentas estados y otras curiosidades.

En el grabado primero, ilustra el corte de estas plumas mediante una orla que enmarca las figuras en complicados arabescos decorativos y de imágenes didácticas, de lectura vertical en tres pasos. La orla es al mismo tiempo un espacio que es utilizado para introducir diez ejemplos diferentes de, corte de pluma, adecuados cada uno de ellos a una función y rallado diferente, proceso que se completa con una segunda estampa en la que incluye tres pasos más de las posiciones de la mano en el acto del corte de la pluma, con las mismas características que en la anterior ilustración.

El texto explica lo esencial del sobre-corte en función de la delicadeza de los perfiles de la letra, especificando aquellas que sirven para la letra sentada, el sobre-corte cuarenta o el grosor de la línea en la orla, para demostrar no solamente el tipo de trazo, sino tambien la manera de no retener fácilmente la tinta, defecto de la grasa que contiene la pluma.

Aunque en la actualidad el material viene proporcionado industrialmente, se sigue manteniendo el criterio de su importancia considerando que pese a la variedad existente en el mercado, para la caligrafía son las de punta recta y ancha, con corte en diagonal, las más apropiadas, que ejecutan un trazo grueso o fino según sea el movimiento de la mano: vertical, horizontal o al sesgo. En cambio en las plumas de punta aguda los rasgos finos o gruesos dependen de la presión que la mano ejerza, conceptos estos muy similares a los explicados por el autor.

El Segundo «Diálogo» (término que resulta curioso, pues en él se detecta la relación maestro-educador) se centra sobre El modo de coger la pluma y conservarla, preceptos que quedan demostrados en el grabado de la estampa cuarta, números 1 y 3 , donde se observa como debe ser cogida con los dedos pulgar e índice, y descansando en la uña del dedo medio. La letra $\mathrm{A}$ del grabado indica el hueco que debe dejarse entre mano y mesa y la letra $\mathrm{C}$ señala la línea figurada paralela y guía con relación a la citada mesa.

Para rasgos, giros, letras mayúsculas y formas, muestra otra posición, la n..$^{\circ}$ 2, afianzando la pluma con los tres dedos y levantando el brazo con movimientos que permitan el trazo que adorna lo escrito.

La conservación del material consiste fundamentalmente en la advertencia de no dejar con tinta las plumas después de la sesión y ser conservadas en tarros de cristal con agua y vinagre, liquido que cubriría la mitad del corte de la pluma. Desde el punto de vista de artista es de capital importancia en todo proceso artístico la conservación del material, pues revierte sobre la obra y el propio autor.

El Tercer Diálogo lo constituyen Los elementos que deben tenerse en la mesa para escribir.

$A E A, \mathrm{LXXV}, 2002,297$, pp. 51 a 88 


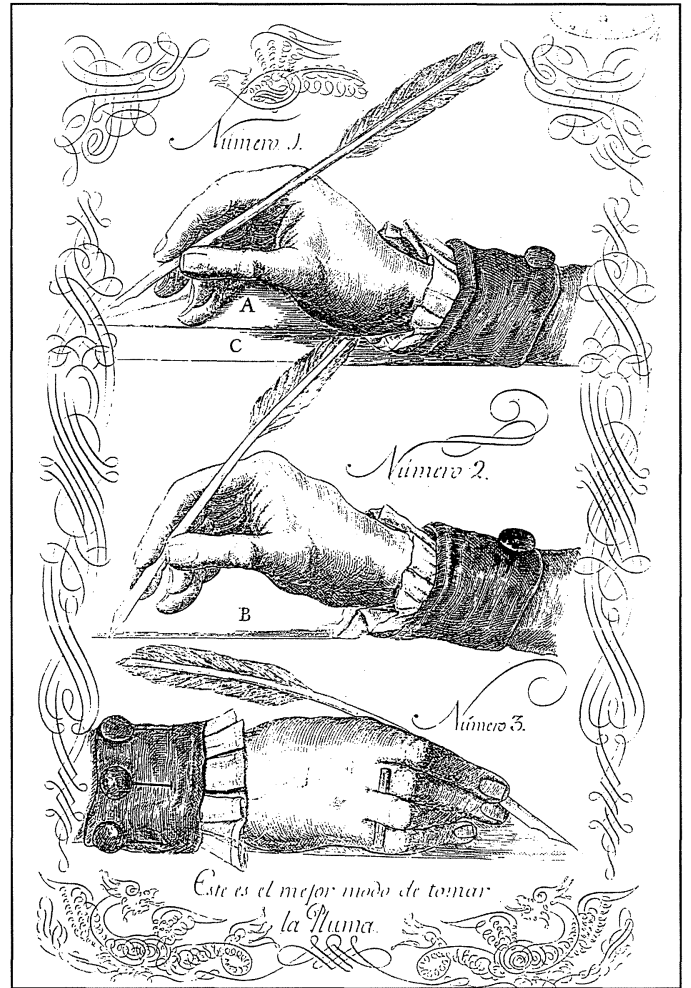

Posiciones de la mano 1 y 3 , anverso y reverso de la mano. F.2, posición para giros.

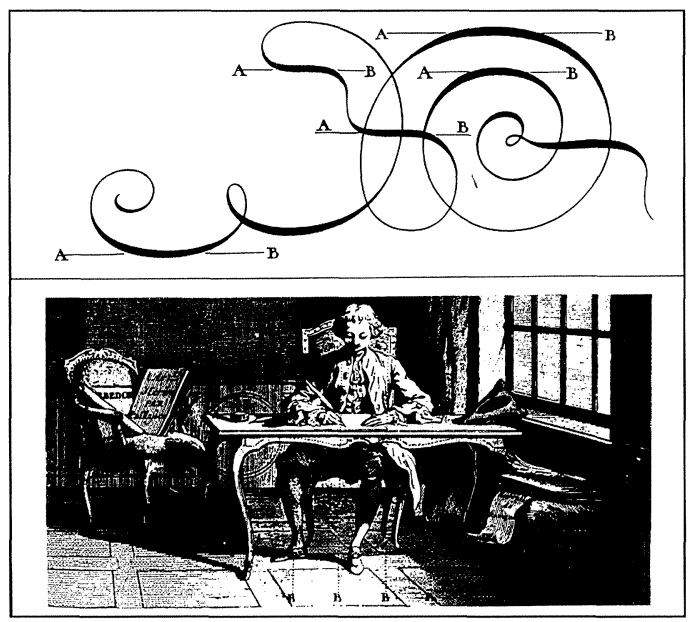

Paillasson, L'art d'écrire, en el $2 .^{\circ}$ volumen de Planchas de la Enciclopedia de Diderot y Alembert, s. XVIII. Grabado por Aubin.

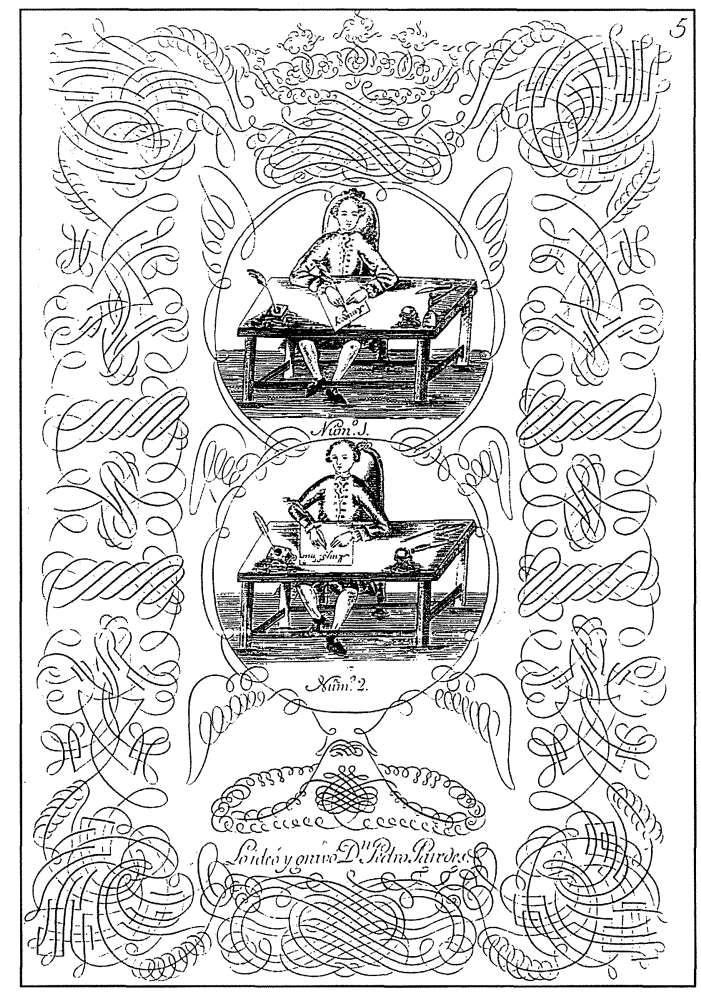

Posición del cuerpo.-Grabado de Paredes, en conexión con el grabado de Aubin, realizados ambos en el mismo siglo.

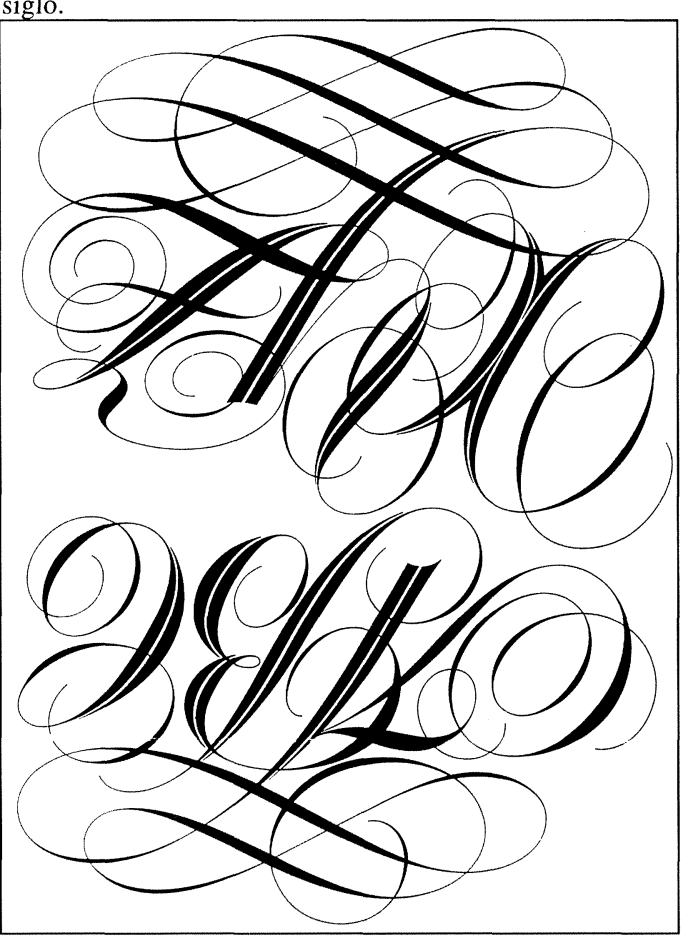

Caligrafía original de Jean Larcher. s. xx.

$A E A, \mathrm{LXXV}, 2002,297$, pp. 51 a 88

http://archivoespañoldearte.revistas.csic.es 
Es un proceso todo él minucioso, fruto también de la dedicación al trabajo y al valor del tiempo en cada época de la vida.

Se consideran todos los elementos «correctos» que faciliten la tarea, dando consejos en lo concerniente a las características de la Mesa y Silla con relación al hombre principios actualmente utilizados en la Ergonomía ${ }^{5}$. Se adapta la postura natural del cuerpo a la mesa y a la silla, como instrumentos igualmente necesarios, en función de si se es niño o adulto, e igualmente se contempla el color verde del Atril como el que menos ofende a la vista, concepto, este último, demostrado posteriormente en los estudios sobre la visión del color.

La Disposición de los Elementos es también reglada, aunque esto varía según la metodología del calígrafo: «A la parte derecha el tintero con buena tinta, papel de buena calidad, pergamino, ó vitela y el regle. Salvadera, compás y lapicera, á la parte izquierda, y para lo que pudiere ofrecerse, polvos de goma de enebro que llaman glasa» ${ }^{6}$.

La fabricación de la tinta es muy curiosa e interesantes los componentes que describe y sus secantes, aconsejando para estos últimos polvos de cal viva o huesos de carnero quemados con los que polvorea la mancha. Como correctores los polvos de goma de enebro o glasa, " de los más blancos, los que molidos, y pasados por tamiz, después de haber rascado con el cuchillo dichos enmendados, se echarán sobre ella en poquisima cantidad, y se restregarán con papel hasta que se desconozca lo que antes estaba mal escrito» ${ }^{7}$. Con respecto al papel aconsejado, se inclina por el de Génova, sin desdeñar aquellos que eran fabricados, en España principalmente en Zaragoza, por lo que da como norma para su elección aquellos que posean suficiente bruñido, cuerpo en las pieles bien curadas y sin manchas, con más de un año hechos.

En la actualidad, como entonces, la elección del papel es una cuestion relacionada con muy diversos factores e incluso con una experiencia personal, pero la práctica permite conocer algunas reglas, como por ejemplo: Galgo para la pluma chata o de escritura cancilleresca o para las plumas finas, papeles con más cuerpo, de superficie mate y sin pelusa, tipo Bristol, Schoeller, Caballo, etc...

Este Cuaderno se cierra con la Cuarta Disposición, ya que la Quinta la incluye en otro de ellos que promete publicar, pero se desconoce su existencia e incluso si se llegó a editar, pues alude con frecuencia al gran coste que le supone.

Es, quizás, esta Cuarta Disposición una de las más bellas por dar igual importancia a la posición o armonía del cuerpo y aquello que se realiza, casi conceptualizando aquella como una parte integradora de un proceso.

«El cuerpo ha de estar apartado de la mesa tres dedos, inclinado moderadamente sobre el papel. La cabeza y el pecho rectos... de modo, que el cuerpo y movimiento señoree el lugar que ocupan, inclinando con gravedad los ojos a lo que se ha de escribir» ${ }^{8}$.

Este ritual es indicado en el Último Grabado, que a su vez desvela la información o coincidencia en el tiempo entre tal grabado y el ejecutado por Aubin en la Enciclopedia o Diccionario razonado de la Artes y los Oficios, publicado por una Sociedad de Hombres de Letras: y puesto en orden por Diderot y Alembert entre 1751 y 1772, precisando en su tiempo las cuestiones concernientes a la escritura, Paillasson, experto escritor que «Reduce el arte de escribir a demostraciones verdaderas y fáciles con explicaciones claras» ${ }^{9}$.

\footnotetext{
${ }^{5}$ Durante el S. xviII ya existía en España la Escuela Gratuita de Diseño, en Barcelona 1775, cuyo objetivo era la educación del dibujo a las exigencias de la producción mecánica y seriada. En el mueble, se adoptan soluciones "cómodas" que facilitan los movimientos en cada caso.

${ }^{6} y^{7}$ Paredes, P. El Arte de Escribir. Edit, Imprenta Viuda de Felipe Teruel, 1792, Murcia, p. 4.

${ }^{8}$ Paredes, P. Obra citada.

9 Blanchard, G. La Letra.. Edit. Ceac, S.A. Barcelona 1988, p. 50.
}

AEA, LXXV, 2002, 297, pp. 51 a 88 
Quizás Paredes quiso dar a conocer su aportación, aunque sus conceptos de perspectiva sean elementales, pues sorprende con un levantamiento de plano de mesa, que es una representación gráfica más descriptiva y de concepción más propia de un desarrollo infantil del dibujo, que real, hecho que no deja de ser curioso.

\section{LA TÉCNICA}

En este apartado es necesario trabajar con cierta precaución, pues el ejemplar del que se dispone es el de imprenta y no el de los grabados originales. Pese a ello, se situará atendiendo a determinados aspectos:

En primer lugar, precisando que el siglo XVIII, en general, es prioritariamente un siglo calcográfico, aunque no son de desdeñar los focos xilográficos que abastecen demandas populares muy concretas y pujantes. El origen sobre la historiografía española sobre el grabado está sin duda en el Discurso histórico sobre el principio y progresos del grabado, de José de Vargas Ponce en 1790.

En segundo lugar, contemplando la situación de los grabadores de provincias, de la que se destaca un hecho curioso e importante: en 1757 la Academia de San Fernando incorpora el grabado a los concursos de premios y este incentivo da su fruto en la clase de Palomino empezando a encontrarse grabadores de otras regiones fuera de Madrid, como es el caso de los murcianos Juan Barcelón y, anteriormente, Espinosa como alumno de Prieto, ambos deseosos de ampliar conocimientos.

Espinosa (Murcia 1772?), además de sus clases, fue fundidor de letras, grabando alguna portada para las actas de la Academia además del plano topográfico de Madrid, hecho por orden del Conde de Aranda. "Destinado a la Casa de la Moneda de Segovia montó una imprenta de la que salieron pequeñas obras maestras de la tipografía de su tiempo, como el poema didáctico La Pintura, de Rejón de Silva (1788), con viñetas de José Vázquez estampadas en tinta bistre, o el Diccionario de las Nobles Artes (Segovial788) en las que se añadían por primera vez en España voces sobre grabado ${ }^{10}$.

Juan Barcelón (Lorca 1739-Madrid 1801), discípulo de Salcillo en dibujo en Murcia, se formó en la Academia madrileña desde 1759 y ganó el premio en 1763, estudiando con Palomino. Es Académico de Mérito en 1777, «dotado con cierta sensibilidad para el paisaje grabó vistas de Reales Sitios, las de Granada para la Antigüedades árabes etc..» ${ }^{11}$.

Ilustró libros como el Quijote en 1780, el Tratado de la pintura de Leonardo, traducido por Rejón de Silva (1784), el Viaje a Constantinopla de José Moreno (1790) y el muy interesante libro Instrucción Metódica sobre los Muares de Joaquín Manuel Fos, con perfecta reproducción de la máquinas empleadas en la fabricación de la seda, los «muares». Además de las consabidas estampas religiosas y los retratos de hombres ilustres, Barcelón es el grabador de los trabajos de Hércules y de una Cartilla para aprender a dibujar, ilustrada para las obras de Joseph de Ribera y editada por la Calcografía de la Imprenta Real.

Existe, pues, una posible reminiscencia de la técnica del grabado en Murcia, unida al hecho, no descartable, de la influencia del grabado valenciano, con más tradición grabadora, sobre Pedro Paredes, «vecino de la ciudad de Alicante, Reyno de Valencia, Obispado de Orihuela», tal como versa la portada de este cuaderno, y calificado como calcógrafo según Albert Berenguer, (1958).

${ }^{10}$ Gallego, A. Historia del Grabado en España. Edit. Cátedra, Madrid, 1972, p. 265

"Páez, E. Juan Barcelón, grabador murciano. En R.A.B.M. 65, 1958, pp. 311-318. 
Había una necesidad sentida en Murcia de renovar las costumbres tradicionales, que hicieron del aprendizaje artístico una simple relación maestro-discípulo sin más compromiso que la enseñanza de los rudimentos o secretos de su arte. Murcia no fue diferente al resto de las ciudades españolas en el siglo XVIII, exigía la necesidad de otras alternativas de formación, entonces carentes de un código de disciplinas útiles y dejada a la libre iniciativa del maestro.

Las ilustraciones que aporta están muy vinculadas a una de las funciones del Grabado de la época, las Ciencias Descriptivas, que para su aplicación y aprendizaje eran trabajadas con una gran cantidad de imágenes explicativas del texto, sin caer en definiciones oscuras o vagas, tal como Diderot expica en su obra «Propectus de la Enciclopedia».

Loś grabados hacen pensar que están configurados con dos planchas de cobre, una para la reproducción de la orla y otra para los grabados descriptivos del tema, hecho muy utilizado en la época con la finalidad de no encarecer las reproducciones y poder utilizar de nuevo determinadas planchas para otros fines. El procedimiento era muy practicado en esta época y como dato curioso se puede ver la orla del grabado practicado de Aznar de Polanco, «San Casiano» (1736) cobre talla dulce, o el grabado titulado «Alegoría de Fernando VII»(12) , obras en las que se puede comprobar lo afirmado. Las planchas podían entintarse y limpiarse de diferentes maneras y también era posible experimentar con valores de tono y atmósfera. A los surcos sobre el metal, trazados por medio del buril se les llamó talla dulce, nombre genérico que actualmente se puede aplicar igualmente a un buril, que lo es por excelencia, que a una punta seca, que a un aguafuerte etc... En definitiva, son calificativos que derivan del procedimiento empleado para la ejecución de los surcos y la manera de incidir sobre el metal.

Con estos razonamientos y otras deducciones de tipo técnico, tímidamente se podría introducir las ilustraciones en la técnica del grabado calcográfico o talla dulce, aunque quizás esto sea un atrevimiento.

Como conclusión de este trabajo se pueden hacer algunas reflexiones:

* La caligrafía es un arte que en la actualidad se ha retomado con una mirada retrospectiva, extrayendo de ella las ideas o puntos de apoyo, con sus reglas, y adecuándola al momento presente. En los momentos de crisis, el artista necesita beber de las fuentes como sostén del nacimiento de un nuevo arte. Es innegable que el grabado nació en función del libro y está todavía, en buena parte, ligado a él.

* D. Pedro Paredes, calcógrafo, resuelve con dignidad cuatro puntos:

Acierto pedagógico del texto y de los gráficos, según el contexto de la época; buena tipografía en la reproducción de sus textos; mimo y acierto en las ilustraciones y aspecto final de armonía y personalidad de artista.

En él prevalecen unas condiciones psicológicas de respeto al oficio y de amor a la disciplina, sirviéndose de la técnica como medio, no como finalidad.

* Los talleres de imprenta de la Murcia del siglo xviII, se suministraban de otras fundiciones de tipos de letra, pero cuidaban los perfiles de ellas, la igualdad de tintaje tanto en la página como entre páginas del texto, la presión justa para que no dejaran huella sobre el papel por exceso o hiciera fallar letras por defecto, son cuidados característicos del impresor. Pese a todo entre el resultado del sistema más perfecto de reproducción y la obra original hay siempre una distancia enorme.

* Determinados estudios en torno a una obra o un artista ilustran no sólo en tendencias, técnicas o estilos, sino en el hallazgo del embrión que luego puede conducir a nuevas ciencias de épocas presentes.

Dra. M. ${ }^{a}$ Gracia Ruiz Llamas

Catedrática de Dibujo Universidad de Murcia.

$A E A, \mathrm{LXXV}, 2002,297$, pp. 51 a 88 